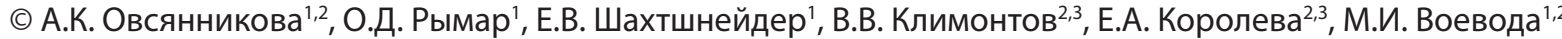

'НИИ терапии и профилактической медицины - филиал ФГБУ «Федеральный исследовательский центр Института цитологии и генетики СО РАН», Новосибирск

${ }_{2}$ «овосибирский государственный университет», Новосибирск

${ }^{3}$ НИИ клинической и экспериментальной лимфологии - филиал ФГБУ «Федеральный исследовательский центр Института цитологии и генетики СО РАН», Новосибирск

Сахарный диабет взрослого типа у молодых (MODY) представляет собой группу заболеваний, связанных с мутацией генов, приводящих к дисфункции $\beta$-клеток поджелудочной железы. Известно 14 вариантов MODY, наиболее изученными являются MODY 1-5. В статье приводится клинический случай MODY 12, в основе которого лежит мутация гена ABCC8, кодирующего рецептор сульфонилмочевины. Диабет дебютировал у мужчины в возрасте 28 лет с гипергликемией до 24 ммоль/л без кетоза. При верификации диагноза выявлены непролиферативная диабетическая ретинопатия, микроальбуминурия, дислипидемия, атеросклероз сонных артерий. Антитела к островковым клеткам и глутаматдекарбоксилазе не выявлены, С-пептид был в норме. Назначена инсулинотерапия в базис-болюсном режиме, доза инсулина постепенно снижалась в связи с гипогликемиями. Препролиферативная диабетическая ретинопатия и макулярный отек выявлены через 4 мес после начала терапии, выполнена панретинальная лазерная фотокоагуляция сетчатки. При проведении молекулярно-генетического исследования верифицирована мутация в гене $A B C C 8$. Идентичная мутация выявлена у матери и дяди пробанда. Инсулин отменен, назначен гликлазид МВ 60 мг/сут, на фоне приема которого сохранялись значительные колебания гликемии. В лечение был присоединен ингибитор глюкозо-натриевого транспортера 2 (SGLT2) дапаглифлозин в дозе 10 мг/сут. На фоне комбинированной терапии отмечено уменьшение вариабельности гликемии. Через 6 мес и 1,5 года сохранялся оптимальный гликемический контроль, эпизодов гипогликемии не зафиксировано. Описание данного случая демонстрирует особенности клинического течения MODY 12 и возможности его лечения комбинацией препарата сульфонилмочевины и ингибитора SGLT2.

КЛЮЧЕВЫЕ СЛОВА: МОDY диабет; мутации; клинический случай; АВСС 8 ген; молекулярно-генетическое исследование; ингибитоpuSGLT2

\section{DIABETES MELLITUS ASSOCIATED WITH THE MUTATION OF THE ABCC8 GENE (MODY 12): FEATURES OF CLINICAL COURSE AND THERAPY}

(c) Alla K. Ovsyannikova ${ }^{1,2}$, Oksana D. Rymar ${ }^{1}$, Elena V. Shakhtshneider ${ }^{1}$, Vadim V. Klimontov²,3 Elena A. Koroleva ${ }^{2,3}$, Mikhail I. Voevoda',2

${ }^{1}$ Research Institute of Internal and Preventive Medicine - Branch of the Institute of Cytology and Genetics, Siberian Branch of Russian Academy of Sciences, Novosibirsk, Russia

${ }^{2}$ Novosibirsk State University, Novosibirsk, Russia

${ }^{3}$ Research Institute of Clinical and Experimental Lymphology - Branch of the Institute of Cytology and Genetics, Siberian Branch of Russian Academy of Sciences, Novosibirsk, Russia

Maturity-Onset Diabetes of the Young (MODY) is a heterogeneous group of diseases associated with genes mutations leading to dysfunction of pancreatic $\beta$-cells. Among the 14 identified MODY variants, MODY $1-5$ are the most studied. The article reports a MODY 12 clinical case, with mutation in ABCC8, encoding the sulphonylurea receptor. Diabetes mellitus manifested in a 27-year-old man with hyperglycaemia up to $24 \mathrm{mmol} / \mathrm{L}$, without ketosis. Non-proliferative diabetic retinopathy, microalbuminuria, dyslipidaemia and carotid atherosclerosis were revealed upon initial examination. The levels of pancreatic islet cell antibodies and glutamate decarboxylase antibodies were negative, while the level of C-peptide was within the normal range. Insulin therapy in the basal-bolus regimen was provided with a gradual dose reduction due to frequent hypoglycaemia. The preproliferative retinopathy with macular oedema was revealed after 4 months of therapy, and panretinal photocoagulation of both eyes was performed. A molecular genetics study revealed a mutation in the gene ABCC8, the same mutation was found in patient's mother and uncle. Insulin therapy was cancelled, and the treatment of gliclazide MR $60 \mathrm{mg} / \mathrm{day}$ was initiated, which resulted in extreme glycaemic excursions. Thereby, sodium-glucose cotranporter-2 (SGLT2) inhibitor dapagliflozin 10 mg/day was added. A reduction in glucose variability parameters were observed on combination therapy. After 6 months till 1.5 years of treatment, glycaemic control was optimal, no hypoglycaemic episodes were observed. This case study demonstrates clinical features of MODY 12, and the potential of combination of sulfonylurea and SGLT2 inhibitor in the treatment of this disease. 
Диабет взрослого типа у молодых (англ. MODY: Maturity-Onset Diabetes of the Young) представляет собой гетерогенную группу заболеваний, в основе которых лежат мутации генов, приводящие к дисфункции $\beta$-клеток поджелудочной железы. Диагностические критерии MODY включают гипергликемию, которая обычно диагностируется в возрасте до 35 лет, аутосомно-доминантный тип наследования с вертикальной передачей по крайней мере в трех поколениях, сходный фенотип болезни у всех членов одной семьи, уровень C-пептида, длительно сохраняющийся в пределах референсных значений [1-3]. Верификация MODY довольно сложна, однако она позволяет выбрать правильную тактику лечения заболевания, обеспечить адекватное ведение беременности, дает возможность выполнить медико-генетическое консультирование в семьях [4-6].

На сегодняшний день известны мутации в 14 генах, приводящие к развитию разных подтипов MODY, которые отличаются между собой распространенностью, клинической картиной и тактикой ведения больных $[1,7,8]$. Несмотря на существенную вариабельность частоты отдельных форм заболевания, в различных популяциях превалируют мутации в генах ядерного фактора гепатоцитов 1a (HNF1A) и глюкокиназы (GCK), приводящие к развитию подтипов MODY 3 и MODY 2 соответственно [9]. На долю этих подтипов приходится до 90\% всех случаев MODY [10]. Наиболее изученными и описанными в литературе являются MODY 1-5. Остальные подтипы встречаются очень редко, данные об их распространенности и особенностях клинического течения фрагментарны.

В данном сообщении мы приводим описание клинического случая MODY 12, связанного с мутацией в гене рецептора к сульфонилмочевине 1 (АВСС8).

\section{ОПИСАНИЕ СЛУЧАЯ}

Под медицинским наблюдением находился пациент А., мужского пола, 28 лет. При первичном обследовании в сентябре 2015 г. предъявлял жалобы на чувство жжения, интенсивные боли в ногах в течение суток, онемение пальцев ног, головные боли, нечеткость зрения.

Из истории заболевания пациента: в феврале 2014 г. появились выраженная сухость во рту, жажда, учащенное мочеиспускание, снижение массы тела (около 5 кг за 4 месяца), интенсивные головные боли, появление которых ни с чем не связывает. При обследовании по месту жительства выявлена гипергликемия натощак до 24 ммоль/л без кетоза, непролиферативная диабетическая ретинопатия (ДР), повышенная экскреция альбумина с мочой (микроальбуминурия). Исследованы антитела к островковым клеткам поджелудочной железы (ICA), антитела к глютаматдекарбоксилазе (GAD), результат отрицательный. Уровень С-пептида составил 338 пмоль/л (норма 298-2350 пмоль/л), гликированного гемоглобина $\left(\mathrm{HbA}_{1 c}\right)-7,1 \%$. Диагностирован сахарный диабет (СД) 1 типа, назначена инсулинотерапия: гларгин 100 Ед/мл 16 Ед перед сном, лизпро по 4-6 Ед перед основными приемами пищи, рамиприл 2,5 мг/сут.

В октябре 2014 г. появились жалобы на ухудшение зрения, при офтальмоскопии выявлена препролиферативная ДР, диабетический макулярный отек сетчатки обоих глаз. В октябре 2014 г. выполнена панретинальная лазеркоагуляция сетчатки (ПЛКС) правого глаза, в феврале 2015 г. - ПЛКС левого глаза.

На фоне инсулинотерапии масса тела увеличилась на 10 кг, отмечались частые легкие гипогликемии в течение суток, доза инсулина постепенно снижалась. $\mathrm{HbA}_{1 c}$ в июне 2015 г. составил 5,1\%. В июле 2015 г. перенес тяжелую гипогликемию, был госпитализирован в стационар, где была отменена инсулинотерапия. На фоне отмены инсулина отмечалось повышение гликемии до 15 ммоль/л, было рекомендовано возобновить инъекции. При поступлении в клинику НИИКЭЛ получал инсулин гларгин 13 Ед перед сном, инсулин лизпро по 4 Ед перед обедом и ужином (перед завтраком инсулин не вводил из-за низких цифр гликемии), суточная доза инсулина составляла $0,3 \mathrm{Eд/ \kappa г.}$

Из анамнеза жизни: рожден от первой беременности на 35-36-й неделе гестации, вес при рождении составлял 2500 г, наблюдалась гидроцефалия. В возрасте 5 лет появились судорожные припадки продолжительностью 1-2 минуты, которые сопровождались кратковременной потерей сознания, возникали самопроизвольно 1 раз в 1-2 месяца и купировались самостоятельно. Обследовался у невролога, были проведены электроэнцефалография, МРТ головного мозга, данных за органическую патологию и эпилепсию не выявлено. Припадки прекратились в возрасте 9 лет, в последующем наблюдалось лишь нарушение мелкой моторики.

Среди родственников пробанда по линии матери СД диагностирован в трех поколениях у 6 человек (у самого пациента, у его матери, ее родных сестры и брата, а также у двух сестер бабушки по линии матери). Все лица с диабетом принимали таблетированные сахароснижающие препараты, дебют диабета приходился на возраст

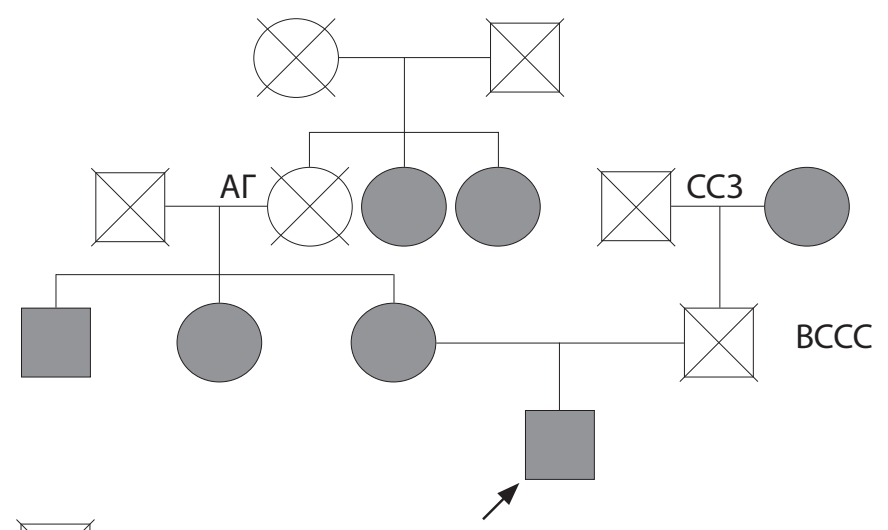

Умершие родственники, мужчины

Умершие родственники, женщины

Родственники с СД, мужчины

Родственники с СД, женщины

Пробанд

Рис. 1. Пациент А. Генеалогическое дерево.

Примечания: АГ - артериальная гипертензия, СС3 - сердечно-сосудистые заболевания, ВССС - внезапная сердечно-сосудистая смерть, ДТП - дорожно-транспортное происшествие. 
около 40 лет (рис. 1); среди родственников отца - сердечно-сосудистые заболевания (ИБС, внезапная смерть) в двух поколениях. У матери пробанда СД с 43 лет, на момент осмотра предъявляла жалобы на сухость во рту, уровень гликемии натощак был до 7 ммоль/л, постпрандиальной - до 11 ммоль/л, НbА составлял 8,1\%, С-пептида - 0,8 нг/мл (норма 0,9-7,1 нг/мл). Из сопутствующих состояний у нее верифицированы артериальная гипертония 1 степени, дислипидемия с преобладанием холестерина липопротеинов низкой плотности, из диабетических осложнений - периферическая нейропатия. Мать пробанда принимала глимепирид 4 мг и метформин 2000 мг в сутки.

При осмотре пациента рост составлял 165 см, вес 68 кг, индекс массы тела - 25 кг/м², пульс ритмичный, 88 в минуту, артериальноедавление(АД) - 140/85 мм рт.ст., признаков патологии внутренних органов нет. В биохимическом анализе крови отмечалось умеренное повышение уровня трансаминаз (АЛТ 78,6 ЕД, АСТ 68,2 ЕД), мочевой кислоты (422,1 мкмоль/л), холестерина липопротеинов низкой плотности (3,41 ммоль/л). Другие показатели оставались в пределах нормы. Уровень $\mathrm{HbA}_{1 с}$ 5,9\%, С-пептида - 1,35 нг/мл (норма 0,9-7,1 нг/мл). Экскреция альбумина с мочой 57,3 мг/л.

При суточном мониторировании АД зафиксированы средние показатели днем 157/96 мм рт. ст., ночью 155/92 мм рт. ст., индекс времени систолической и диастолической гипертензии повышен на протяжении суток (99\% и 93\% соответственно). УзИ сердца: клапаны интактны, две дополнительные хорды левого желудочка, фракция выброса 62\%. Ультразвуковая допплерография: атеросклероз брахиоцефальных артерий на экстракраниальном уровне, гемодинамически незначимая бляшка в левой общей сонной артерии с распространением во внутреннюю сонную артерию. При проведении УзИ щитовидной железы, брюшной полости и почек патологии не выявлено. Электромиография: выраженная дистальная сенсорная нейропатия. При МРТ головного мозга выявлены единичные мелкие хронические неспецифические очаги в структуре базальных ядер и в белом веществе полушарий, признаки атрофических изменений мозговой ткани в перивентрикулярном белом веществе полушарий дисциркуляторного характера, снижение кровотока по правой позвоночной артерии.

На фоне инсулинотерапии гларгином 10 Ед вечером и инсулином лизпро 4 Ед перед ужином наблюдались следующие значения гликемии: 8.00 - 5,2 ммоль/л, 11.00 3,7 ммоль/л, 13.00 - 7,4 ммоль/л, 17.00 - 13,7 ммоль/л, 20.00 - 7,6 ммоль/л.

Учитывая особенности течения заболевания (семейная агрегация СД, частые гипогликемии при введении небольших доз инсулина, сохранный уровень С-пептида, отсутствие антиостровковых антител), высказано предположение о наличии MODY. Проведено полноэкзомное секвенирование генов, ассоциированных с известными подтипами MODY 1-14. Диагностирована миссенс-мутация His321Pro в гене PAX4 (ассоциирована с MODY 9), а также мутация Ala1457Thr в гене ABCC8 (ассоциирована с MODY 12). Выявленные замены были подтверждены с помощью автоматического секвенирования по Сенгеру. Мутация His321Pro в гене PAX4, выявленная в гетерозиготном варианте, является высокочастотным по-

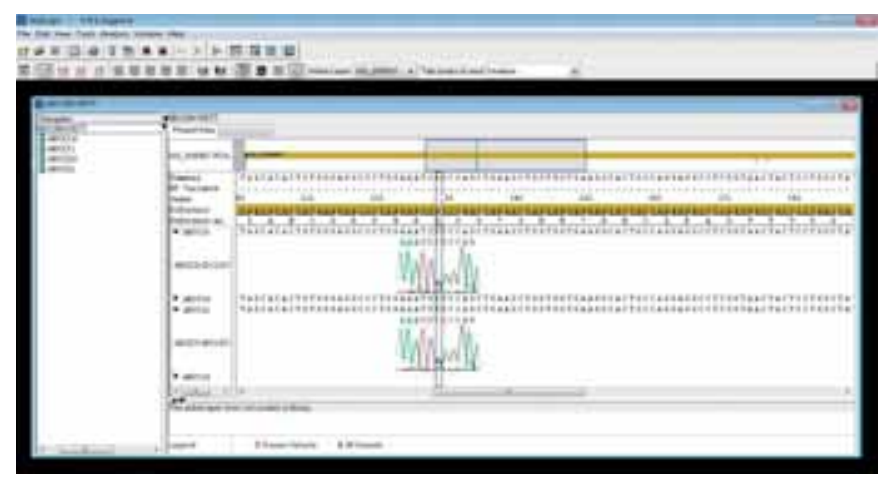

Рис. 2. Мутация p.Ala1457Thr, выявленная у пробанда.

лиморфизмом и не приводит к развитию клинических проявлений. Мутация в позиции 1457 гена $A B C C 8$ является редкой, приводит к замене аланина на триптофан в структуре кодируемого белка (рис. 2). У матери и дяди пробанда также выявлена мутация Ala1457Thr в гене ABCC8.

С помощью онлайн-программы прогнозирования структуры белка PolyPhen-2 получены данные о высокой вероятности повреждающего действия мутации Ala1457Thr на функцию продукта гена ABCC8 - рецептора к сульфонилмочевине 1.

Учитывая наличие дислипидемии, выполнено молекулярно-генетическое исследование ряда генов, вовлеченных в регуляцию обмена липидов: APOA1, APOA2, APOA4, APOA5, APOB, APOC3, APOD, LDLR, LDLRAP1, LPL, PCSK9, SCARB1 и SREBF2. Вклад в развитие дислипидемии у данного пациента может вносить полиморфизм Gly2Ser в экзоне 1 гена SCARB1, кодирующего белок SRB1 - рецептор липопротеидов высокой плотности, а также нонсенс-мутация Ser474Ter в экзоне 9 гена липопротеинлипазы $L P L$.

После получения результатов молекулярно-генетического исследования предпринята попытка отмены инсулинотерапии и пробного лечения гликлазидом МВ в дозе 60 мг/сут. На фоне приема гликлазида МВ в течение недели отмечались значительные колебания гликемии 3,6-12,9 ммоль/л. Пациенту проведен непрерывный мониторинг гликемии (НМг) в режиме реального времени с помощью системы Medtronic Paradigm MMT-722. Peзультаты НМГ на 4-7-й день приема гликлазида МВ представлены на рис. 3.

Учитывая значительную вариабельность гликемии, эпизоды гипергликемии и тенденцию к гипогликемии натощак, дальнейшее увеличение дозы гликлазида представлялось нецелесообразным. Назначена комбинированная терапия гликлазидом MB 60 мг/сут и дапаглифло-

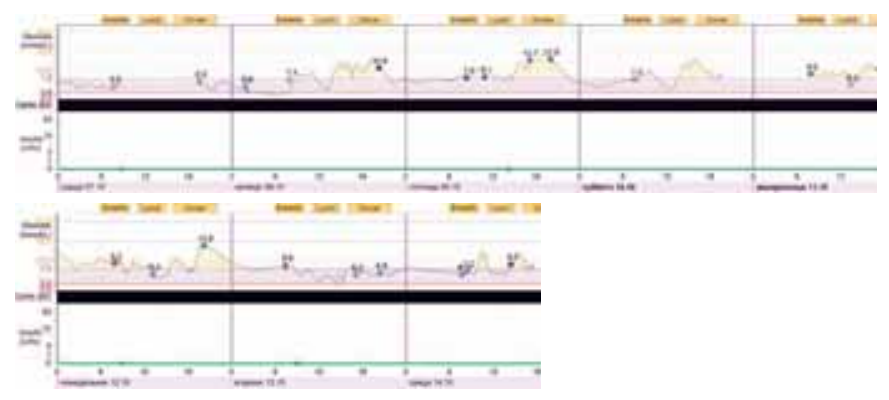

Рис. 3. Результаты непрерывного мониторинга гликемии на фоне приема гликлазида МВ 60 мг/сут (первый график) и на фоне приема комбинированной терапии (второй график). 
зином 10 мг/сут. На фоне приема препаратов отмечено снижение колебаний гликемии, эпизоды гипогликемии не зафиксированы.

Через 6 мес терапии уровень $\mathrm{HbA}_{1 с}$ составил 6,0\%, показатели глюкозы плазмы натощак в пределах 4,3-6,2 ммоль/л, в течение дня 6-7 ммоль/л (данные самоконтроля гликемии глюкометром). Снижения уровня глюкозы ниже 3,8 ммоль/л и клинических проявлений гипогликемических состояний не было, масса тела пациента снизилась на 4 кг. Через 1,5 года пациент продолжает принимать назначенную сахароснижающую терапию, целевые значения показателей углеводного обмена достигнуты.

После верификации мутации у матери пробанда ей также была проведена коррекция терапии: вместо глимепирида назначен гликлазид МВ по 60 мг в сутки, отменен метформин. На фоне монотерапии у пациентки не были достигнуты целевые показатели углеводного обмена, при увеличении дозы глимепирида наблюдались гипогликемии. Учитывая положительный эффект применения глимепирида в сочетании с дапаглифлозином у пробанда его матери также был рекомендован препарат из класса ингибиторов SGLT2. Пациентка начала принимать эмпаглифлозин 25 мг в сутки в дополнение к гликлазиду MB 60 мг, через месяц уровень гликемии был в пределах целевых показателей, уровень $\mathrm{HbA}_{1 с}$ через 3 мес составлял 7,4\%.

\section{ОБСУЖДЕНИЕ}

Представленный случай демонстрирует особенности течения СД, связанного с редкой мутацией в гене $A B C C 8$, кодирующем рецептор сульфонилмочевины 1. Как известно, у пациентов молодого возраста с нарушением углеводного обмена могут быть верифицированы СД 1 типа, СД 2 типа или моногенные формы СД. У данного пациента в дебюте заболевания отсутствовали некоторые симптомы, характерные для наиболее распространенных типов СД. Не совсем типичными были отсутствие кетонурии и кетоацидоза, отрицательные антитела к GAD и ICA, которые можно выявить более чем в 70\% случаев во время манифестации СД 1 типа [11]. Уровень С-пептида был в норме, что, однако, может наблюдаться на ранних этапах клинического течения СД 1 типа. У пациента отсутствовали ожирение, клинические проявления инсулинорезистентности, такие как acantosis nigricans, характерные для СД 2 типа с ранним дебютом [6]. О возможности отнесения СД к MODY свидетельствовало наличие СД как минимум в трех поколениях, сохранение секреции С-пептида и очевидные признаки передозировки инсулина при введении относительно небольших доз на втором году клинического течения заболевания. Точное время возникновения гипергликемии у данного пациента неизвестно, нельзя исключить скрытое течение болезни до клинического дебюта.

Особенностью течения СД у наблюдавшегося нами пациента явилась сравнительно поздняя (в 27 лет) клиническая манифестация заболевания, сопровождавшаяся повышением гликемии до высоких цифр, отсутствие кетоза, развитие микрососудистых осложнений (ретино-, нефро- и нейропатии) при небольшой длительности клинического течения заболевания, быстрое про- грессирование ДР, сочетание диабета с артериальной гипертензией, дислипидемией, гиперурикемией, неврологической патологией, раннее (относительно возраста) появление признаков атеросклероза брахиоцефальных артерий. В литературе не описаны диабетические осложнения, ассоциированные с MODY12 диабетом. В нашем клиническом случае у пробанда диагностированы ранние микрососудистые осложнения, развитие которых, возможно, связано с изменениями в генах липидного обмена. У пациента верифицирована миссенс-замена rs4238001 (p.Gly2Ser) в гене SCARB1 в гомозиготном варианте по редкому аллелю Т $(\mathrm{MAF}=0,06)$. С помощью онлайн-программы прогнозирования структуры белка PolyPhen-2 получены данные о высокой вероятности повреждающего действия rs4238001 на функцию белка, кодируемого геном SCARB1 (score Polyphen2 - 1.000). Ген SCARB1 - scavenger receptor class B member 1 - один из нескольких рецепторов на поверхности клеток, которые играют важную роль в регулировании метаболизма липопротеинов, участвуя в транспорте эфиров холестерина [12]. Полиморфизм гена SCARB1 ассоциирован с плазменными уровнями холестерина липопротеинов высокой плотности, триглицеридами и АРОВ. Мутации в гене SCARB1 могут быть причиной развития дислипидемии [13]. По данным литературы, нонсенс-замена в гене LPL (rs328, p.Ser474Ter) ассоциирована с развитием гипертриглицеридемии [14]. Дислипидемия, диагностированная у пациента, может быть обусловлена структурными изменениями в генах липидного обмена и приводить к более тяжелому течению диабета и раннему развитию осложнений со стороны сердечно-сосудистой системы. Изменения в генах липидного обмена также выявлены у матери пробанда.

Молекулярно-генетическое исследование выявило мутацию в гене $A B C C 8$, приводящую к замене аланина на триптофан в структуре кодируемого этим геном белка. Последний представляет собой вторую субъединицу АТФ-чувствительных калиевых каналов $\beta$-клеток поджелудочной железы - рецептора к сульфонилмочевине (SUR1). Первую субъединицу, белок Kir6.2, кодирует ген KCNJ11, ассоциированный с развитием MODY13 диабета. Четыре Kir6.2-субъединицы образуют поры канала и каждый из них связан с SUR-субъединицей, которая регулирует работу канала [15]. Закрытие АТФ-чувствительных калиевых каналов необходимо для глюкозо-стимулированной секреции инсулина $\beta$-клетками, открытие же этих каналов ингибирует секрецию инсулина. АТФ-зависимый калиевый канал, кодируемый генами KCNJ11 и $A B C C 8$, является терапевтической мишенью для препаратов группы сульфонилмочевины [16]. Большинство мутаций в этих генах приводят к развитию неонатального СД и не отличаются по клиническим проявлениям [17]. Некоторые мутации в АBCС8 вызывают развитие гипогликемического гиперинсулинизма в младенческом возрасте [18].

Мутации ABCC8 ассоциированы с развитием MODY12, СД 2 типа, гестационным и неонатальным СД. В литературе описаны единичные случаи ABCC8-MODY, которые отличаются по клиническому течению. Выявлена мутация в гене $A B C C 8$ в трех поколениях одной семьи, напоминающая дефицит глюкокиназы (MODY2), с «мягкой» гипергликемией, не требующей медикаментозного лечения [19]. 
Представляет интерес клинический случай с описанием судорог неясного генеза в детском возрасте у отца пробанда с MODY12, у которого также верифицирован СД, ассоциированный с мутацией в гене $A B C C 8$, в возрасте 28 лет [20]. У представленного нами пациента также в детском возрасте был судорожный синдром, при этом эпилепсия и другие органические неврологические заболевания были исключены. Судороги в сочетании с неонатальным диабетом являются клиническими проявлениями DEND-синдрома (developmental delay, epilepsy, and neonatal diabetes), к которому также относятся отставание в развитии и эпилепсия [21]. Данный синдром ассоциирован с мутациями в гене KCNJ11. При патологических изменениях в данном гене нарушается функция Kir2 АТФ-чувствительных калиевых каналов, расположенных не только в $\beta$-клетках поджелудочной железы, но и в нейронах, что проявляется неврологическими симптомами. При мутациях в АBCС8 также наблюдается дисфункция каналов, но за счет субъединицы SUR1, расположенной в поджелудочной железе и нейронах. Возможно, наличие судорог при MODY12 является следствием мутации в гене $A B C C 8$ и, так же как и при DEND-синдроме, сочетается с развитием СД, но в более позднем возрасте. Данное предположение требует дальнейшего изучения.

Носители мутаций в гене $A B C C 8$ обычно чувствительны к препаратам сульфонилмочевины (ПСМ), что связано с действием данного класса препаратов на SUR-peцепторы, функция которых нарушается при MODY12 [18]. Описано несколько клинических случаев, в которых у пациентов с MODY12 определялись гипогликемии на небольшие дозы инсулина, и у всех наблюдалась высокая чувствительность к ПСМ $[22,23]$. У описанного нами пациента лечение гликлазидом МВ в средней терапевтической дозе оказалось довольно эффективным, но сопровождалось значительной вариабельностью гликемии (ВГ). Накапливаются данные, что высокая ВГ является фактором риска развития микрососудистых осложнений и макроангиопатий [24]. С учетом быстрого развития сосудистых поражений у пациента представлялось важным избежать эпизодов гипо- и гипергликемии, тем самым уменьшить ВГ. Таким образом, нужен был второй сахароснижающий препарат с минимальным риском гипогликемий, снижающий ВГ и имеющий инсулиннезависимый механизм действия [25]. Всеми этими характеристиками обладают препараты класса ингибиторов глюкозо-натриевого котранспортера 2 типа (SGLT2) [26, 27]. Поэтому пациенту была назначена комбинация гликлазида и дапаглифлозина с положительным эффектом. У матери пробанда также были достигнуты целевые значения показателей углеводного обмена при приеме ПСМ и ингибиторов SGLT2. Ранее было описано применение инги- биторов SGLT2 среди моногенных форм СД только при MODY3, назначать рекомендовалось с осторожностью, так как при мутации в гене HNF1A снижен почечный порог для глюкозы, и назначение данного класса препаратов может вызвать дегидратацию и урогенитальную инфекцию [28]. Насколько нам известно, данное сообщение является первым описанием в российской литературе применения ингибитора SGLT2 в лечении пациентов с MODY. Инсулиннезависимый механизм действия ингибиторов SGLT2 позволяет рассматривать эти препараты как весьма перспективные для лечения пациентов с генетически обусловленной дисфункцией $\beta$-клеток, не имеющих склонности к кетоацидозу, в случае неэффективности или недостаточной эффективности ПСМ.

\section{ЗАКЛЮЧЕНИЕ}

Представленный случай демонстрирует особенности клинического течения и возможности терапии СД, связанного с мутацией гена $A B C C 8$, кодирующего рецептор сульфонилмочевины 1 (подтип MODY12). Персонифицированный подход к диагностике и лечению особенно важен при выявлении неклассического течения СД у лиц молодого возраста.

\section{ДОПОЛНИТЕЛЬНАЯ ИНФОРМАЦИЯ}

Финансирование работы. Молекулярно-генетические исследования выполнены в НИИТПМ-филиал ИЦиГ СО РАН за счет гранта Российского научного фонда (№14-15-00496-П). Клиническое обследование пациента проведено в НИИ клинической и экспериментальной лимфологии - филиал ИЦиГ СО РАН за счет средств государственного задания.

Конфликт интересов. Авторы декларируют отсутствие конфликта интересов, связанного с публикацией настоящей статьи.

Согласие пациента. Проведенная работа соответствует нормам GCP. Протокол и информированный листок пациентов для участия в исследовании рассмотрен и одобрен в Этическом комитете «НИИТПМ», протокол №2 от 11.02.2014. Пациенты добровольно подписали информированное согласие на публикацию персональной медицинской информации в журнале «Сахарный диабет».

Участие авторов. Овсянникова А.К. - сбор и обработка материала, анализ полученных данных, написание текста; Рымар О.Д. - концепция и дизайн исследования, редактирование текста рукописи; Шахтшнейдер Е.В. - выполнение молекулярно-генетического исследования, написание текста; Климонтов В.В. - клиническое обследование пациента, написание текста; Королёва Е.А. - клиническое обследование пациента, написание текста; Воевода М.И. - концепция и дизайн исследования. Все авторы внесли существенный вклад в проведение анализа исследований, подготовку статьи, прочли и одобрили финальную версию перед публикацией.

\section{СПИСОК ЛИТЕРАТУРЫ | REFERENCES}

1. Петеркова В.А., Кураева ТЛ., Зильберман Л.И., и др. Генетические дефекты функции бета-клетки. В кн.: Сахарный диабет: многообразие клинических форм. Под ред. И.И. Дедова, М.В. Шестаковой. - М.: Медицинское информационное агентство; 2016. - С. 89-113. [Peterkova VA, Kuraeva TL, Zilberman LI, et al. Genetic defects in beta cell function. In: Dedov II, Shestakova MV, editors. Diabetes mellitus: a variety of clinical forms. Moscow: Medtsinskoe informatsionnoe agentstvo; 2016. (In Russ.)]
2. зубкова Н.А., Арбатская Н.Ю., Петряйкина Е.Е., и др. Сахарный диабет типа MODY3: клиническая и молекулярно- генетическая характеристика 9 случаев заболевания // Проблемы эндокринологии. - 2014. - Т. 60. — №1. — C. 51-56. [Zubkova NA, Arbatskaya NY, Petryaikina EE, et al. Type 3 form of MODY: the clinical and molecular-genetic characteristic. Nine cases of the disease. Problems of endocrinology. 2014;60(1):51-56. (In Russ.)] doi: 10.14341/probl201460151-56 
3. Fajans SS, Bell GI. MODY: history, genetics, pathophysiology, and clinical decision making. Diabetes Care. 2011;34(8):1878-1884. doi: 10.2337/dc11-0035

4. Ovsyannikova AK, Rymar OD, Ivanoshchuk DE, et al. A Case of Maturity Onset Diabetes of the Young (MODY3) in a Family with a Novel HNF1A Gene Mutation in Five Generations. Diabetes Ther. 2018;9(1):413-420. doi: 10.1007/s13300-017-0350-8

5. Воевода М.И., Иванова А.А, Шахтшнейдер Е.В., и др. Молекулярно-генетические основы MODY-диабета // Терапевтический архив. — 2016. - T. 88. — №4. - C. 117-124. [Voevoda MI, Ivanova AA, Shakhtshneider EV, et al. Molecular genetics of maturity-onset diabetes of the young. Ter Arkh. 2016;88(4):117-124. (In Russ.)] doi: 10.17116/terarkh2016884117-124

6. Кураева Т.Л., Сечко Е.А., Еремина И.А., и др. Особенности течения MODYз у ребенка с фенотипом сахарного диабета 2 типа // Сахарный диабет. — 2013. — T. 16. — №2. — C. 88-93. [Kuraeva TL, Sechko EA, Eremina IA, et al. MODY3 in the child with type 2 diabetes mellitus phenotype: case report. Diabetes mellitus. 2013;16(2):88-93. (In Russ.)] doi: 10.14341/2072-0351-3762

7. McDonald TJ, Ellard S. Maturity onset diabetes of the young: identification and diagnosis. Ann Clin Biochem. 2013;50(Pt 5):403-415. doi: $10.1177 / 0004563213483458$

8. Bonnefond A, Philippe J, Durand E, et al. Whole-exome sequencing and high throughput genotyping identified KCNJ11 as the thirteenth MODY gene. PLoS One. 2012;7(6):e37423. doi: 10.1371/journal.pone.0037423

9. Delvecchio M, Ludovico O, Menzaghi C, et al. Low prevalence of HNF1A mutations after molecular screening of multiple MODY genes in 58 Italian families recruited in the pediatric or adult diabetes clinic from a single Italian hospital. Diabetes Care. 2014;37(12):e258-260. doi: 10.2337/dc14-1788

10. Thanabalasingham G, Owen KR. Diagnosis and management of maturity onset diabetes of the young (MODY). BMJ. 2011;343:d6044. doi: 10.1136/bmj.d6044

11. Chen YC, Tung YC, Liu SY, et al. Clinical characteristics of type 1 diabetes mellitus in Taiwanese children aged younger than 6 years: A single-center experience. J Formos Med Assoc. 2017;1 16(5):340-344. doi: 10.1016/j.jfma.2016.07.005

12. Vickers KC, Rodriquez A. Human scavenger receptor class B type I variants, lipid traits, and cardiovascular disease. Circ Cardiovasc Genet. 2014;7(6):735-737. doi: 10.1161/CIRCGENETICS.114.000929

13. Vergeer M, Korporaal SJ, Franssen R, et al. Genetic variant of the scavenger receptor Bl in humans. N Eng/ J Med. 2011;364(2):136-145. doi: 10.1056/NEJMoa0907687

14. Caussy C, Charriere S, Meirhaeghe A, et al. Multiple microRNA regulation of lipoprotein lipase gene abolished by 3'UTR polymorphisms in a triglyceride-lowering haplotype harboring p.Ser474Ter. Atherosclerosis. 2016;246:280-286. doi: 10.1016/j.atherosclerosis.2016.01.010

15. Girard CA, Wunderlich FT, Shimomura K, et al. Expression of an activating mutation in the gene encoding the KATP channel subunit Kir6.2 in mouse pancreatic beta cells recapitulates neonatal diabetes. J Clin Invest. 2009;119(1):80-90. doi: https://doi.org/10.1172/JCl35772
16. Haghvirdizadeh P, Mohamed Z, Abdullah NA, et al. KCNJ11: Genetic Polymorphisms and Risk of Diabetes Mellitus. J Diabetes Res. 2015;2015:908152. doi: 10.1155/2015/908152

17. Yang Y, Chan L. Monogenic Diabetes: What It Teaches Us on the Common Forms of Type 1 and Type 2 Diabetes. Endocr Rev. 2016;37(3):190-222. doi: 10.1210/er.2015-1116

18. Haghverdizadeh P, Sadat Haerian M, Haghverdizadeh P, Sadat Haerian B. ABCC8 genetic variants and risk of diabetes mellitus. Gene. 2014:545(2):198-204. doi: 10.1016/j.gene.2014.04.040

19. Gonsorcikova L, Vaxillaire M, Pruhova S, et al. Familial mild hyperglycemia associated with a novel ABCC8-V84I mutation within three generations. Pediatr Diabetes. 2011;12(3 Pt 2):266-269. doi: 10.1111/j.1399-5448.2010.00719.x

20. Harel S, Cohen AS, Hussain K, et al. Alternating hypoglycemia and hyperglycemia in a toddler with a homozygous P.R1419H ABCC8 mutation: an unusual clinical picture. J Pediatr Endocrinol Metab. 2015;28(3-4):345-351. doi: 10.1515/jpem-2014-0265

21. Evliyaoglu O, Ercan O, Ataoglu E, et al. Neonatal Diabetes: Two Cases with Isolated Pancreas Agenesis due to Homozygous PTF1A Enhancer Mutations and One with Developmental Delay, Epilepsy, and Neonatal Diabetes Syndrome due to KCNJ11 Mutation. J Clin Res Pediatr Endocrinol. 2018;10(2):168-174. doi: 10.4274/jcrpe.5162

22. Bowman P, Flanagan SE, Edghill EL, et al. Heterozygous ABCC8 mutations are a cause of MODY. Diabetologia. 2012;55(1):123-127. doi: 10.1007/s00125-011-2319-x

23. Riveline JP, Rousseau E, Reznik Y, et al. Clinical and metabolic features of adult-onset diabetes caused by ABCC 8 mutations. Diabetes Care. 2012;35(2):248-251. doi: 10.2337/dc11-1469

24. Климонтов В.В., Мякина Н.Е. Вариабельность гликемии при сахарном диабете: инструмент для оценки качества гликемического контроля и риска осложнений // Сахарный диабет. 2014. - T. 17. — №2. - C. 76-82. [Klimontov W, Myakina NE. Glycaemic variability in diabetes: a tool for assessing the quality of glycaemic control and the risk of complications. Diabetes mellitus. 2014;17(2):76-82. (In Russ.)] doi: 10.14341/DM20142

25. Кононенко И.В., Смирнова О.M. SGLT2: Новые подходы к комбинированной терапии // Медицинский Совет. — 2016. — №3. C. 10-16. [Kononenko IV., Smirnova OM. SGLT2: Novye podkhody k kombinirovannoj terapii. Meditsinskiy Sovet. 2016;(3):10-16. (In Russ.)] doi: 10.21518/2079-701X-2016-3-10-17

26. Nishimura R, Osonoi T, Kanada S, et al. Effects of luseogliflozin, a sodium-glucose co-transporter 2 inhibitor, on 24-h glucose variability assessed by continuous glucose monitoring in Japanese patients with type 2 diabetes mellitus: a randomized, double-blind, placebo-controlled, crossover study. Diabetes Obes Metab. 2015;17(8):800-804. doi: $10.1111 /$ dom. 12481

27. Henry RR, Rosenstock J, Edelman S, et al. Exploring the potential of the SGLT2 inhibitor dapagliflozin in type 1 diabetes: a randomized, double-blind, placebo-controlled pilot study. Diabetes Care. 2015;38(3):412-419. doi: 10.2337/dc13-2955

28. Stride A, Ellard S, Clark P, et al. Cell Dysfunction, Insulin Sensitivity, and Glycosuria Precede Diabetes in Hepatocyte Nuclear Factor-1 Mutation Carriers. Diabetes Care. 2005;28(7):1751-1756. doi: 10.2337/diacare.28.7.1751

ИНФОРМАЦИЯ ОБ АВТОРАХ [AUTHORS INFO]

*Овсянникова Алла Константиновна, к.м.н. [Alla K. Ovsyannikova, MD, PhD]; адрес: 630089, Новосибирск, ул. Бориса Богаткова, д. 175/1 [address: 175/1 Borisa Bogatkova st., Novosibirsk, 630089 Russian Federation]; ORCID: http://orcid.org/0000-0002-9669-745X; eLibrary SPIN 7431-5997; e-mail: aknikolaeva@bk.ru

Рымар Оксана Дмитриевна, д.М.H. [Oksana D. Rymar, MD, PhD]; ORCID: http://orcid.org/0000-0003-4095-016; eLibrary SPIN: 8345-9365; e-mail: orymar23@gmail.com

Шахтшнейдер Елена Владимировна, к.м.н., в.н.с. [Elena V. Shakhtshneider, PhD]; ORCID: http://orcid.org/0000-0001-6108-1025; eLibrary SPIN- 9453-9067; e-mail: 2117409@mail.ru Климонтов Вадим Валерьевич, д.м.н., профессор [Vadim V. Klimontov, MD, PhD, Professor]; ORCID: http://orcid.org/0000-0002-5407-8722; e-Library SPIN: 1734-4030; e-mail: klimontov@mail.ru Королева Елена Анатольевна, к.м.н, С.н.с. [Elena A. Koroleva, MD, PhD, senior research associate] ORCID: http://orcid.org/0000-0002-8629-7030; e-Library SPIN: 9085-1716; e-mail: ekoro@bk.ru

Воевода Михаил Иванович, д.М.н., профессор, академик PAH [Mikhail I. Voevoda, MD, PhD, Professor]; ORCID: http://orcid.org/0000-0001-9425-413X; e-Library SPIN: 6133-1780; e-mail: mvoevoda@ya.ru 


\section{ЦИТИРОВАТЬ:}

Овсянникова А.К., Рымар О.Д., Шахтшнейдер Е.В., Климонтов В.В., Королева Е.А., Воевода М.И. Сахарный диабет, связанный с мутацией гена ABCC8 (MODY 12): особенности клинического течения и терапии // Сахарный диабет. 2019. — T. 22. — №1. — C. 88-94. doi: 10.14341/DM9600

\section{TO CITE THIS ARTICLE:}

Ovsyannikova AK, Rymar OD, Shakhtshneider EV, Klimontov VV, Koroleva EA, Voevoda MI. Diabetes mellitus associated with the mutation of the ABCC8 gene (MODY 12): features of clinical course and therapy. Diabetes Mellitus. 2019;22(1):88-94.

doi: $10.14341 / D M 9600$ 